\title{
Language Teaching and Cambridge University Press Christopher Brumfit Essay Prize 2020
}

Language Teaching announces the award of an essay prize which honours one of the founding editors of this journal.

\section{Prize}

1. The winner will receive a $\mathfrak{E 5 0 0}$ credit to be used to purchase books available in the current Cambridge University Press (CUP) catalogue.

2. The winning essay - revised where appropriate in line with referees' comments - will be prioritised for publication in the first available issue of the journal.

3. The winner will be nominated for a one-year period as a member of the Language Teaching Editorial Board and designated in all outlets of the journal as the Christopher Brumfit Award Winner member.

4. An official certificate will be issued to the winner by the journal and Cambridge University Press.

\section{Subject}

Write an essay which addresses critically an aspect or aspects of applied linguistics or second language acquisition which you are interested in.

\section{Procedure}

1. The prize will be awarded in open competition and only one entry is permitted per person. The competition is open to any early-career scholar, defined as a registered student currently on a doctoral course not yet in possession of a doctoral degree, or a post-doctoral scholar within five years of the award of the doctorate at the time of submission.

2. Together with their essay file, authors must enclose a scanned letter on official notepaper from their supervisor, or from a person of similar academic standing, attesting to their status. Authors must also attest that the submission is their work, not published elsewhere and not currently submitted to any other publication. The essay must not have been submitted to this or any other essay competition in previous years. However, an essay may be a reworked piece of the entrant's course work provided that it was originally the sole creation of the entrant. Any form of plagiarism will result in automatic disqualification.

3. Essays should be a maximum length of 4,000 words INCLUDING references.

4. Essays should be presented in English, in a pdf or MS Word file, and APA format.

5. The closing date for submissions is $\mathbf{3 0}$ November 2020. Submissions and status letters should be sent as file attachments in an email to the Editor of Language Teaching, editorlanguageteaching@ gmail.com. Essays should not present any author information.

6. All entries will be acknowledged and initially read in-house before short-listing. Unfortunately, we do not have the capacity to provide feedback on unsuccessful entries.

7. In awarding the prize, the committee will also take into consideration the originality of the submitted paper and the theoretical and/or empirical contribution it makes to the discipline.

8. The prize will be awarded by Cambridge University Press and Language Teaching on the recommendation of the referees formed from the Editorial Board of the journal. The winner will be 
announced on the journal website by 1 March 2021. The Board's decision is final. If no submission is judged suitable, the prize will not be awarded.

9. The Editor may also commission for publication in Language Teaching any entries that are highly commended by the referees.

Cite this article: (2020). Language Teaching and Cambridge University Press Christopher Brumfit Essay Prize 2020. Language Teaching, 53(1), 1-2. https://doi.org/10.1017/S0261444819000405 